\title{
Organometallics for Electronics
}

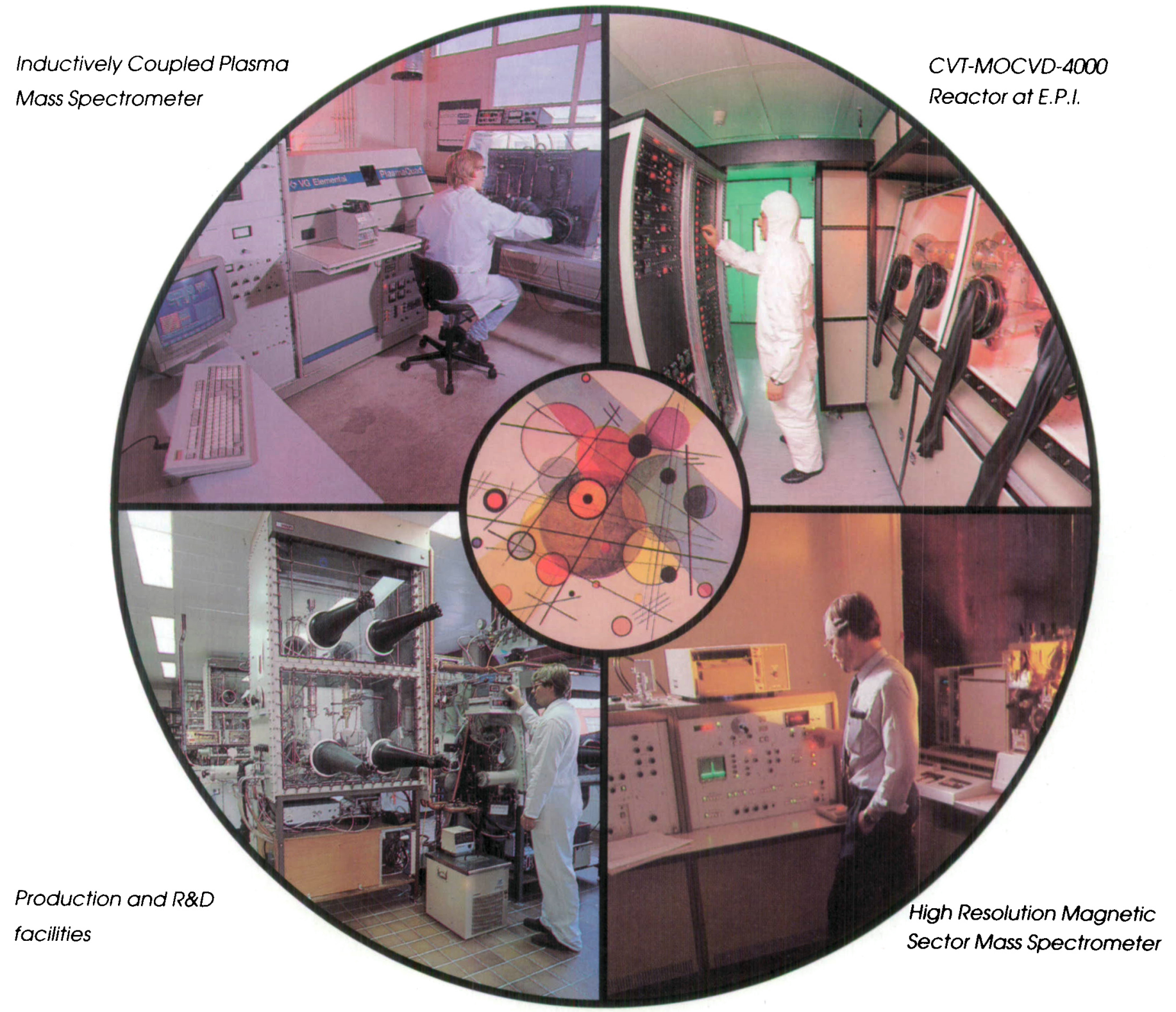

Organometallics produced and analysed by Billiton Precursors B.V.* are tested by Epitaxial Products International Ltd. ensuring products of consistent high performance. A Certificate of Analysis and a Certificate of Performance are supplied with each batch.

TMG Typical 77K mobility for GaAs (100 mbar, $\left.650^{\circ} \mathrm{C}, \mathrm{V} / 111=110\right):>120.000 \mathrm{~cm}^{2} \mathrm{~V}^{-1} \mathrm{~s}^{-1}$

TMA Typical 10K FWHM of Bound Exciton for $\mathrm{Al}_{0.25} \mathrm{Ga}_{0.75} \mathrm{As}\left(1000 \mathrm{mbar}, 750^{\circ} \mathrm{C}, \mathrm{V} / \mathrm{III}=36\right):<5 \mathrm{meV}$ Typical 5K FWHM of Bound Exciton for $\mathrm{Al}_{0.10} \mathrm{Ga}_{0.90^{A s}}$ ( $\left.1000 \mathrm{mbar}, 800^{\circ} \mathrm{C}, \mathrm{V} / 1 \mathrm{ll}=15\right)$ : $<4 \mathrm{meV}$

TMI To follow shortly

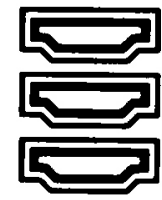

Tel (Intl)31-85-654882. Fax (Intl)31-85-654664. Telex 75026 bires nl

Billiton Metals Japan K.K. * . Mr H. Neriishi, Kasumigaseki Bldg 29 ,

2-5, Kasumigaseki 3-chome, Chiyoda-Ku. Tokyo 100, Japan.

Tel (Intl)81-3-581-6303. Fax (Int1)81-3-592-0903. Telex j22373. j22901. 
